\title{
CORRESPONDENCE
}

\section{Choosing the right or left for the subclavian venous cannulation?}

\author{
Hyo-Seok Na ${ }^{1}$, Hyun-Jung Shin ${ }^{1}$ and Jin-Hee Kim ${ }^{1,2^{*}}$ (D)
}

(0) 2019 Springer-Verlag GmbH Germany, part of Springer Nature

Dear Editor,

We thank Lavillegrand and Maury for their comments [1] about our recent publication [2].

First, the different cannulation time is probably due to a different sonographic view as well as the cannulation site. The needle path including needle tip should be visualized throughout the subclavian vein (SCV) cannulation via a long-axis view, which is inevitable and makes the time for cannulation longer in the SCV group than in the IJV group. Therefore, the longer cannulation time in the SCV implies a complexity of visualization of needle path in the long-axis view as well as a technical difficulty in the SCV cannulation, which might favor the IJV cannulation.

Second, based on the previous results of Tarbiat et al. [3] and Schummer et al. [4], preferring the cannulation of left SCV to right SCV seems reasonable. However, these studies were designed to be observational studies and the central venous catheterization was performed using anatomical landmarks. Nonetheless, Schummer et al. [4] reported a very low incidence of arterial puncture in landmark-guided left SCV cannulation (0.6\%), which is quite similar to our one observed in ultrasound-guided right SCV cannulation (0.6\%). Accordingly, ultrasoundguided cannulation of left SCV may be able to lower the occurrence of mechanical complication rate. A further study comparing the outcomes of the ultrasound-guided left and right SCV cannulation is required to obtain critical information that decides the preference of the $\mathrm{SCV}$ cannulation site.

\begin{abstract}
Author details
${ }^{1}$ Department of Anesthesiology and Pain Medicine, Seoul National University Bundang Hospital, Seongnam, South Korea. ${ }^{2}$ Department of Anesthesiology and Pain Medicine, Seoul National University College of Medicine, Seoul, South Korea.
\end{abstract}

Compliance with ethical standards

Conflicts of interest

On behalf of all authors, the corresponding author declares no conflicts of interest.

\section{Publisher's Note}

Springer Nature remains neutral with regard to jurisdictional claims in published maps and institutional affiliations.

Accepted: 27 July 2019

Published online: 6 September 2019

\section{References}

1. Lavillegrand J, Maury E (2019) Always choosing the left for the subclavian venous cannulation? Intnesive Care Med https://doi.org/10.1007/s0013 4-019-05699-7

2. Shin HJ, Na HS, Koh WU, Ro YJ, Lee JM, Choi YJ, Park S, Kim JH (2019) Complications in internal jugular vs subclavian ultrasound-guided central venous catheterization: a comparative randomized trial. Intensive Care Med 45:968-976

3. Tarbiat M, Manafi B, Davoudi M (2014) Comparison of the complications between left side and right side subclavian vein catheter placement in patients undergoing coronary artery bypass graft surgery. J Cardiovas Thorac Res 6:147-153

4. Schummer W, Schummer C, Rose N, Niesen W-D, Sakka SG (2007) Mechanical complications and malpositions of central venous cannulations by experienced operators: a prospective study of 1794 catheterizations in critically ill patients. Intensive Care Med 33:1055-1059 